\section{Investigation of the effect of 8-week training applied to children 14-16 years old on motor performance}

\section{4-16 yaş çocuklara uygulanan 8 haftalık antrenmanin motor performans üzerine etkisinin incelenmesi}

\author{
Tuğba Urcan ${ }^{1}$ \\ Rüçhan İri' ${ }^{2}$
}

\begin{abstract}
The aim of the study is to examine the effect of eight-week-long training in different branches on motor performance for children aged 14-16. A total of 96 volunteers, including 69 people who are engaged in sports in different branches (tennis, volleyball and basketball) and 27 people who are sedentary, using an 8-week training program, 3 days a week, participated in the study. Motor performance development of the participants was determined with the Tennis Condition Test protocol (KTT). Paired Samples t-test was used to determine the difference between the pre-test and post-tests of the data, and the One-Way Analysis of Variance ANOVA test was used to determine the difference between the groups. As a result of this study, it was determined that 8-week branch-specific training applied to children between the ages of 14-16 improved motor performance. In order to increase the motor performance development of children in this age group, it is important to direct them to sports activities in line with their abilities. To apply it is thought that the training plans,
\end{abstract}

\section{Özet}

Çalışmanın amacı, 14-16 yaş grubu çocuklara uygulanan sekiz haftalık farklı branşlardaki antrenmanlarin, motor performans üzerine etkisinin incelenmesidir. Çalışmaya haftada 3 gün olmak üzere, 8 haftalık antrenman programı uygulayan farklı branşlarda (tenis, voleybol ve basketbol ) antrenman yapan 69 kişi ve sedanterlerden oluşan 27 kişi olmak üzere toplam 96 gönüllü katılmıştır. Katılımcıların, motor performans gelişimleri Tenis Kondisyon Test protokolü (KTT) ile belirlenmiştir. Verilerin ön test ile son testleri arasındaki fark1 belirlemede Paired Samples t-testi, gruplar arasındaki farkı belirlemede Tek Yönlü Varyans Analizi olan ANOVA testi kullanılmıştır. Yapılan bu çalışma sonucunda, 14-16 yaş grubu çocuklara uygulanan 8 haftalık branşa özgü antrenmanların, motor performansı geliştirdiği belirlenmiştir. $\mathrm{Bu}$ yaş grubundaki çocukların, motor performans gelişimlerini artırabilmek için, yetenekleri doğrultusunda sportif faliyetlere yönlendirilmesi önem taşımaktadır. Uygulanacak olan antrenman planlarının, branşa özgü ve temel motor performans gelişimini

\footnotetext{
1 Tuğba Urcan Niğde Ömer Halisdemir Üniversitesi, Spor Bilimleri Fakültesi, tugbaurcan@gmail.com iD Orcid ID: 0000-0002-5844-3096

2 Prof. Dr., Niğde Ömer Halisdemir Üniversitesi, Spor Bilimleri Fakültesi, ruchaniri@,ohu.edu.tr (iD) Orcid ID: 0000-0002-6520-873X
} 
Urcan, T., \& İri, R. (2020). 14-16 yaş çocuklara uygulanan 8 haftalık antrenmanın motor performans üzerine etkisinin incelenmesi. Journal of Human Sciences, 17(4), 1094-1105. doi:10.14687/ihs.v17i4.6074

which are specific to the branch and of a type that will support basic motor performance development, are important for the development of the basic motor characteristics and motor performance levels of children in the 14-16 age group.

Keywords: Tennis, Volleyball, Basketball, KTT, 14-16 years old, Tennis Condition Test.

(Extended English summary is at the end of this document) destekleyecek türde olması 14-16 yaş grubundaki çocukların temel motorik özelliklerinin ve motorik performans düzeylerinin geliştirilmesinde önemli olduğu düşünülmektedir.

Anahtar Kelimeler: Tenis, Voleybol, Basketbol, KT'T, 14-16 yaş, Tenis Kondisyon Testi.

\section{Giriş}

Motor beceri, bireylerin çeşitli motor görevlerde ustaca performans gösterme derecelerinin yanı sıra, belirli bir performansin temelini oluşturan hareket kalitesi, koordinasyon ve kontrolü temsil eden bir terimdir (Robinson ve ark., 2015). Motor performans ise, bir hareket ya da bir fiziksel aktivite becerisini gerçekleştirme olarak tanımlanır ve motor performans bir motor becerinin yapılabilme düzeyini ifade eder (Gallahue ve ark., 2014). Tüm bunlar zeka, yaş, genel motivasyon kaygısı, yorgunluk, çevresel faktörlerin yanı sıra özellikle düzenli yapılan antrenmanlar ile yakından ilişkilidir (Sayın, 2011; Timmons ve ark., 2007).

Son yıllarda spor ve sporcu performansı alanındaki çalssmalardaki ilerlemeler büyük ilgi görmekte ve özellikle çocuklar ve ergenlerin motor performans durumlarını belirlemeye yönelik çalışmaların sayısı artmaktadır (Leppanen ve ark., 2016). Bunun nedeni, motor performansın çocukların sağlık durumları ve sportif başarılarını ortaya koyan güçlü bir gösterge olmasıdır (Vandorpe ve ark., 2012). Literatürde bu durumu destekleyen birçok çalışma mevcuttur. Bu durumun önemini vurgulayan bir çalışmada, 14-16 yaş aralığındaki çocuklar da cinsiyet faktörünü göz önünde bulundurarak kapsamlı bir araştırma yapılmış ve bu çalışmada motor performansın cinsiyete göre nasıl değiştiği araştırılmıştır. Sonuç olarak, cinsiyet ve fiziksel uygunluğun motor performans düzeyinde farklılıklar meydana getirmesinin muhtemel olduğu vurgulanmışır (Sackett ve Edwards, 2019). Fransen ve ark. (2012) motor yeterliliği yüksek olan çocukların fiziksel uygunluk testlerinde daha başarılı oldukları ve çeşitli spor branşlarına daha sık katıldıklarını bildirmiştir. Özellikle yerli literatürde farklı spor branşlarında faaliyet gösteren, ergen çocukların motor performansını inceleyen az sayıda çalışma bulunmaktadır. Çocukların, farklı spor branşlarına yönelmeleri, yapılan spor branşının karakteristik özelliklerine göre motor performans düzeyleri arasında farklılıklara neden olabilir. Tüm bu bilgiler ışı̆̆ında yapmış olduğumuz çalışmada, farklı branşlarda antrenman yapan kız çocuklarının motor performans düzeylerinin belirlenmesi ve farklı branşlarda yapılan antrenmanların, motor performans üzerine olan etkisinin incelenmesi amaçlanmıştur. Çalışmada uygulanmış olan Alman Tenis Federasyonunun geliştirmiş olduğu Tenis Kondisyon testinin (KTT) Türkiye'deki çocuklara daha önce uygulanmamış olması çalışmanın özgünlüğünü ifade etmektedir.

\section{Materyal Metot}

Çalışmaya Niğde Gençlik ve Spor İl Müdürlüğü bünyesinde 3 farklı branşta antrenmanlarını sürdüren, 14-16 yaş grubu 21 tenisçi, 23 basketbolcu, 25 voleybolcu ve 27 sedanter olmak üzere toplam 96 sağlıklı kız çocuğu katılmıştır. Çalışmaya katılan katılımcıların, boy uzunlukları $0.1 \mathrm{~cm}$ hassasiyeti olan çelik stadiometre ile "cm" cinsiden, ağırlı ölçümleri ise yine $0.1 \mathrm{~kg}$ hassasiyetle ölçüm yapan Sinbo marka dijital baskül ile "kg" cinsinden ölçülmüştür. Katıllmcıların vücut kitle indeksleri (VKI) vücut ağırlığının, boy uzunluğunun karesine bölünmesi ile [VKI = Ağırlık (kg) / Boy $\left(\mathrm{m}^{2}\right)$ ] hesaplanmıştır. Çalışma ön test-son test deneysel model yöntemi ile gerçekleştirilmiştir. 
Urcan, T., \& İri, R. (2020). 14-16 yaş çocuklara uygulanan 8 haftalık antrenmanın motor performans üzerine etkisinin incelenmesi. Journal of Human Sciences, 17(4), 1094-1105. doi:10.14687/ihs.v17i4.6074

Uygulanan testler öncesi katıllmcllara testlerle ilgili bilgi verilmiş olup, testlerden önce $10 \mathrm{dk}$. 1sınma uygulanmıştır. İlk olarak, katılımcı gruplarına ön test uygulamaları gerçekleştirilmiştir. Tenis, voleybol ve basketbolculara haftada 3 gün olmak üzere antrenörler tarafindan 8 haftalık branşlarına özgü teknik taktik ve motor becerileri geliştiren bir program uygulanmıştur. Sedanter gruba ise, herhangi bir antrenman programı uygulanmamıştır. Antrenmanlar, $10 \mathrm{dk}$. 1sınma, $45 \mathrm{dk}$. ana bölüm ve $10 \mathrm{dk}$. soğuma olacak şekilde toplamda $65 \mathrm{dk}$. olarak planlanmıştır. 8 haftalık antrenman dönemi sonrasında katılımcıların son test uygulamaları gerçekleştirilmiştir.

\section{Motor Performans Ölçümleri \\ Tenis Kondisyon Testi ( KTT )}

KTT, Alman Tenis Federasyonu Spor Danışma Kurulu adına Heidelberg Üniversitesi Spor Bilimleri Enstitüsü'nde Klaus Bös ve ark. (2004) tarafindan geliştirilmiştir. Test 6 alt birim testten oluşmakta ve 11-17 yaş arası kişilere uygulanmaktadır. Her test aşamasında testin sonucunda kaydedilen ve test protokol kâğıdına işlenen puanlara göre katulımcıların başarısı, KTTT değerlendirme tablolarına göre yorumlanmaktadır. Test başlamadan önce katılımcılara testler hakkında bilgi verilmiş ve testlere teker teker alınmışlardır.

\section{Sarkaç-Sürat Koşusu (22 m)}

Başlangıç çizgisi üzerinde testi uygulayacak kişi, bir ayağı önde olacak şekilde hazır vaziyette beklemiş ve başla komutu ile koşmaya başlamıştur. Belirlenen mesafe koşularak dönüş noktasına kadar ilerlendikten sonra, hızlıca başlangıç noktasına doğru koşularak düdük sesi ile birlikte kronometre durdurulmuştur. Katılımcı bu testi iki kez uygulamış ve katulımcının en iyi derecesi sn cinsinden kaydedilmiştir.

\section{Çift El Sağlık Topu Atma (2kg)}

Test katılımcının $2 \mathrm{~kg}$ ağırlığındaki sağlık topunu başının üzerinden çift elle atabileceği en uzak noktaya atması şeklinde uygulanmıştır. Test iki kez uygulanmış ve topun düştügü yer ile başlangıç çizgisi arasındaki mesafe $\mathrm{cm}$ cinsinden ölçülerek katılımcının en iyi derecesi kayıt formuna kaydedilmiştir.

\section{Üç Adım Atlama}

Katılımcı mümkün olduğunca en uzak noktaya 3 adım ile atlamaya çalışmıştır. Katılımcının en son çift ayağını bastığı yer ile başlangıç çizgisi arasındaki mesafe ölçülmüş ve $\mathrm{cm}$ cinsinden kaydedilmiştir.

\section{Şınav Çekme (60 sn.)}

Testi uygulayacak olan kişi bacaklar kapalı pozisyonda yerde yüz üstü uzanmış, eller kalçanın üzerinde beklemiştir. Katılımcı hazır olduğunda eller ön tarafa alınarak şınav pozisyonunda kollarla vücut yukarı kaldırılmıştır. Ellerden biri diğerinin üzerine dokunarak tekrar arka kısma geri çekilmesi ve ilk başlama pozisyonuna yüz üstü durumuna tekrar gelip, eller kalça üzerinde birbirine vurulması ve tekrarlanması şeklinde uygulanmışır. 60 saniye içerisinde mümkün olan en fazla sayıya ulaşılmaya çalışılmış ve geçerli olarak yapılan şınav sayısı adet cinsinden kaydedilmiştir.

\section{Saniye Sarkaç Koşusu}

Katulımcı tenis kortunun dip çizginin, 1 metre içerisinde hazır halde beklemiştir. Çizginin bir tarafina dışarı doğru bir bant yapıştırılmış ve başlama noktası olarak belirlenmiştir. Başla komutu ile 45 saniye içerisinde iki çizgi arasında mümkün olan en fazla gidiş-gelişi yapmaya çalışması şeklinde uygulanmıştır. Dönüşlerde katılımcıdan sağ taraftaki çizgiye sağ ayakla, sol taraftaki çizgiye sol ayakla dokunması istenmiştir. Süre bitiminde gidiş-geliş şeklinde kaç tur atıldığı kaydedilmiştir.

\section{Dakika Koşu Testi}

Katılımcı sahanın dip köşesine yerleştirilmiş huninin yanında hazır bir vaziyette beklemiştir. Katılımcı başla komutu ile koşmaya başlamış ve $12 \mathrm{dk}$. bittiğinde test sonlandırılmıştur. Ölçümler test kayıt formuna tur sayısı olarak kaydedilmiştir. 
Urcan, T., \& İri, R. (2020). 14-16 yaş çocuklara uygulanan 8 haftalık antrenmanın motor performans üzerine etkisinin incelenmesi. Journal of Human Sciences, 17(4), 1094-1105. doi:10.14687/jhs.v17i4.6074

\section{Genel Değerlendirme}

Toplam KTT puanı, yaş ve Cinsiyet faktörüne göre skorlar her bir alt birimi, motor katsayısına dönüştürülerek belirlenmiştir. Toplam KTT puanı motor beceri puanına dönüştürülerek çok iyi, iyi, orta, yeterli ve zayıf olarak 5 seviyede sinıflandırılmıstır (Tablo 1).

Tablo 1. Toplam KT'T puanı sinıflandırılması

\begin{tabular}{cccc}
\hline Z-Değeri & \%-Değeri & Değerlendirme & Kategorisi \\
\hline$>115$ & $94-100$ & Çok iyi & 1 \\
\hline $106-115$ & $69-93$ & İyi & 2 \\
\hline $96-105$ & $31-68$ & Orta & 3 \\
\hline $86-95$ & $7-30$ & Yeterli & 4 \\
\hline $86<$ & $0-6$ & Zayıf & 5 \\
\hline
\end{tabular}

\section{Verilerin Analizi}

Çalışmada elde edilen veriler, SPSS 22.0 paket programında analiz edilmiştir. Yapılan testler sonucunda verilerin normal dağılım gösterdiği belirlenmiştir. Grupların kendi içlerinde ön test ve son test sonuçları arasındaki farkllığı belirlemek için parametrik testlerden eşleştirilmiş örneklem Paired Samples t-testi, gruplar arasındaki farklıllğ̆ belirlenmede tek yönlü varyas analizi ANOVA testi uygulanmıştır. Anlamlı farklılığın hangi, grup lehine olduğunu belirlemek adına Post-hoc testlerinden Tukey testi kullanılmıştır. Çalışmanın anlamlılık düzeyi $\mathrm{p}<0,05$ olarak kabul edilmiştir.

\section{Bulgular}

Tablo 2. Voleybol katılımcılarının ön test ve son test ölçüm alt test değerlerinin karşılaştırıldığı ttesti

\begin{tabular}{|c|c|c|c|c|c|c|c|c|c|}
\hline \multirow{2}{*}{ Değişken } & \multirow[b]{2}{*}{ Eşli Grup } & \multirow{2}{*}{$\mathrm{N}$} & \multirow{2}{*}{$\bar{x}$} & \multirow{2}{*}{ S.S } & \multicolumn{2}{|c|}{ İkili Arasındaki Farklar } & \multirow[b]{2}{*}{$\mathrm{t}$} & \multirow[b]{2}{*}{$\mathrm{sd}$} & \multirow[b]{2}{*}{$\mathrm{p}$} \\
\hline & & & & & $\bar{x}$ & S.S. & & & \\
\hline \multirow{2}{*}{ Sarkaç Koşusu } & Ön Test & 25 & 93,44 & 8,36 & \multirow{2}{*}{$-14,72$} & \multirow{2}{*}{9,27} & \multirow{2}{*}{$-7,94$} & \multirow{2}{*}{24} & \multirow{2}{*}{$0,00^{*}$} \\
\hline & Son Test & 25 & 108,16 & 4,96 & & & & & \\
\hline \multirow{2}{*}{$\begin{array}{c}\text { Sağlık Topu } \\
\text { Atma }\end{array}$} & Ön Test & 25 & 98,56 & 7,71 & \multirow{2}{*}{3,20} & \multirow{2}{*}{12,40} & \multirow{2}{*}{1,29} & \multirow{2}{*}{24} & \multirow{2}{*}{0,21} \\
\hline & Son Test & 25 & 95,36 & 7,80 & & & & & \\
\hline \multirow{2}{*}{ Üç Adım Atlama } & Ön Test & 25 & 87,36 & 9,67 & \multirow{2}{*}{$-5,60$} & \multirow{2}{*}{9,87} & \multirow{2}{*}{$-2,84$} & \multirow{2}{*}{24} & \multirow{2}{*}{$0,01^{*}$} \\
\hline & Son Test & 25 & 92,96 & 6,66 & & & & & \\
\hline \multirow{2}{*}{ Şınav (60 sn.) } & Ön Test & 25 & 97,76 & 9,54 & \multirow{2}{*}{$-9,36$} & \multirow{2}{*}{10,58} & \multirow{2}{*}{$-4,42$} & \multirow{2}{*}{24} & \multirow{2}{*}{$0,00^{*}$} \\
\hline & Son Test & 25 & 107,12 & 7,55 & & & & & \\
\hline \multirow{2}{*}{$\begin{array}{c}45 \text { Sn. Sarkaç } \\
\text { Koşusu }\end{array}$} & Ön Test & 25 & 89,92 & 12,05 & & & 424 & 4 & $000 *$ \\
\hline & Son Test & 25 & 104,72 & 12,18 & $-14,80$ & $1 /, 4$ & $-4,24$ & 24 & $0,00^{*}$ \\
\hline 12 & Ön Test & 25 & 109,28 & 12,59 & & & -185 & 24 & 008 \\
\hline & Son Test & 25 & 115,92 & 11,95 & -( & 1 & 5 & 24 & 8 \\
\hline Norm Değerler & Ön Test & 25 & 576,24 & 40,76 & -4576 & 5800 & -395 & 24 & $000 *$ \\
\hline Toplamı & Son Test & 25 & 622,00 & 41,10 & $-43, / 0$ & 58,00 & $-5,90$ & $\angle 4$ & $0,00^{n}$ \\
\hline $7 \mathrm{D}$ & Ön Test & 25 & 95,76 & 6,78 & -1.56 & & $-3,89$ & 24 & $0,00 *$ \\
\hline Z Degen & Son Test & 25 & 103,32 & 6,86 & - - & 9,13 & $-Ј, 0$ ' & 24 & \\
\hline Genel & Ön Test & 25 & 3,20 & 0,96 & & & & 4 & \\
\hline Değerlendirme & Son Test & 25 & 2,72 & 0,79 & U, & 10 & 2,01 & 24 & J,05" \\
\hline
\end{tabular}


Urcan, T., \& İri, R. (2020). 14-16 yaș çocuklara uygulanan 8 haftalık antrenmanın motor performans üzerine etkisinin incelenmesi. Journal of Human Sciences, 17(4), 1094-1105. doi:10.14687/jhs.v17i4.6074

Tablo 2 incelendiğinde voleybolcuların sarkaç koşusu, üç adım atlama, şınav, 45 sn. sarkaç koşu testi, norm değerler toplamı ve $Z$ değerinde son testler lehine anlamlı fark tespit edilmiştir $(\mathrm{p} \leq 0,05)$.

Tablo 3. Basketbol katılımcılarının ön test ve son test ölçüm alt test değerlerinin karşılaştırıldığı t-testi

\begin{tabular}{|c|c|c|c|c|c|c|c|c|c|}
\hline \multirow{2}{*}{ Değişken } & \multirow{2}{*}{ Eşli Grup } & \multirow{2}{*}{$\mathrm{N}$} & \multirow{2}{*}{$\bar{x}$} & \multirow{2}{*}{ S.S. } & \multicolumn{2}{|c|}{ İkili Arasındaki Farklar } & \multirow[b]{2}{*}{$\mathrm{t}$} & \multirow{2}{*}{ sd } & \multirow[b]{2}{*}{$\mathrm{p}$} \\
\hline & & & & & $\bar{x}$ & S.S. & & & \\
\hline \multirow{2}{*}{ Sarkaç Koşusu } & Ön Test & 23 & 94,52 & 5,73 & \multirow{2}{*}{$-8,52$} & \multirow{2}{*}{10,76} & \multirow{2}{*}{$-3,80$} & \multirow{2}{*}{22} & \multirow{2}{*}{$0,00^{*}$} \\
\hline & Son Test & 23 & 103,04 & 8,96 & & & & & \\
\hline \multirow{2}{*}{ Sağlık Topu Atma } & Ön Test & 23 & 92,70 & 8,75 & \multirow{2}{*}{$-0,61$} & \multirow{2}{*}{11,35} & \multirow{2}{*}{$-0,26$} & \multirow{2}{*}{22} & \multirow{2}{*}{0,80} \\
\hline & Son Test & 23 & 93,30 & 7,15 & & & & & \\
\hline \multirow{2}{*}{ Üç Adım Atlama } & Ön Test & 23 & 103,83 & 9,68 & \multirow{2}{*}{14,26} & \multirow{2}{*}{13,91} & \multirow{2}{*}{4,92} & \multirow{2}{*}{22} & \multirow{2}{*}{$0,00^{*}$} \\
\hline & Son Test & 23 & 89,57 & 11,33 & & & & & \\
\hline \multirow{2}{*}{ Şınav (60 sn.) } & Ön Test & 23 & 89,91 & 9,64 & \multirow{2}{*}{$-1,57$} & \multirow{2}{*}{9,83} & \multirow{2}{*}{$-0,76$} & \multirow{2}{*}{22} & \multirow{2}{*}{0,45} \\
\hline & Son Test & 23 & 91,48 & 7,01 & & & & & \\
\hline \multirow{2}{*}{$\begin{array}{c}45 \text { Sn. Sarkaç } \\
\text { Koşusu }\end{array}$} & Ön Test & 23 & 100,00 & 14,31 & & & & & \\
\hline & Son Test & 23 & 96,35 & 12,31 & 3,65 & 15,22 & 1,15 & 22 & 0,26 \\
\hline & Ön Test & 23 & 90,70 & 13,49 & 200 & 1575 & 061 & 22 & 055 \\
\hline $12 \mathrm{DK} . \mathrm{Koşu}$ & Son Test & 23 & 88,70 & 10,49 & 2,00 &, 13 & 0,01 & 22 & 0,כ5 \\
\hline Norm Değerler & Ön Test & 23 & 561,43 & 44,84 & $-5,04$ & 45,53 & -0.53 & 22 & 0.60 \\
\hline Toplam1 & Son Test & 23 & 566,48 & 35,75 & $-5,04$ & 45,55 & $-0,35$ & 22 & 0,00 \\
\hline 7 Dĕ̌eri & Ön Test & 23 & 93,65 & 7,94 & -043 & 851 & -025 & 22 & 081 \\
\hline Lignti & Son Test & 23 & 94,09 & 6,09 & - & , & $-0,23$ & 22 & 0,01 \\
\hline Genel & Ön Test & 23 & 3,52 & 0,85 & -009 & & & 22 & 8 \\
\hline Değerlendirme & Son Test & 23 & 3,61 & 0,78 & $-0,09$ & 1,00 & $-0,42$ & 22 & 0,00 \\
\hline
\end{tabular}

Tablo 4. Tenis katulımcılarının ön test ve son test ölçüm alt test değerlerinin karşılaştırıldığı t-testi

\begin{tabular}{|c|c|c|c|c|c|c|c|c|c|}
\hline \multirow{2}{*}{ Değişken } & \multirow{2}{*}{ Eşli Grup } & \multirow{2}{*}{$\mathrm{N}$} & \multirow[t]{2}{*}{$\bar{x}$} & \multirow[t]{2}{*}{ S.S. } & \multicolumn{2}{|c|}{$\begin{array}{l}\text { İkili Arasındaki } \\
\text { Farklar }\end{array}$} & \multirow[t]{2}{*}{$\mathrm{t}$} & \multirow[t]{2}{*}{ sd } & \multirow{2}{*}{$\mathrm{p}$} \\
\hline & & & & & $\overline{\bar{x}}$ & S.S. & & & \\
\hline \multirow{2}{*}{ Sarkaç Koşusu } & Ön Test & 21 & 88,57 & 9,12 & \multirow{2}{*}{5,62} & \multirow{2}{*}{12,08} & \multirow{2}{*}{2,13} & \multirow{2}{*}{20} & \multirow{2}{*}{$0,05^{*}$} \\
\hline & Son Test & 21 & 82,95 & 7,97 & & & & & \\
\hline \multirow{2}{*}{ Sağl1k Topu Atma } & Ön Test & 21 & 86,67 & 8,30 & \multirow{2}{*}{$-1,24$} & \multirow{2}{*}{12,81} & \multirow{2}{*}{$-0,44$} & \multirow{2}{*}{20} & \multirow{2}{*}{0,66} \\
\hline & Son Test & 21 & 87,90 & 6,97 & & & & & \\
\hline \multirow{2}{*}{ Üç Adım Atlama } & Ön Test & 21 & 85,24 & 8,50 & \multirow{2}{*}{0,67} & \multirow{2}{*}{13,63} & \multirow{2}{*}{0,22} & \multirow{2}{*}{20} & \multirow{2}{*}{0,83} \\
\hline & Son Test & 21 & 84,57 & 8,18 & & & & & \\
\hline \multirow{2}{*}{ Şınav (60 sn.) } & Ön Test & 21 & 88,19 & 19,97 & \multirow{2}{*}{$-5,52$} & \multirow{2}{*}{22,90} & \multirow{2}{*}{$-1,11$} & \multirow{2}{*}{20} & \multirow{2}{*}{0,28} \\
\hline & Son Test & 21 & 93,71 & 9,37 & & & & & \\
\hline \multirow{2}{*}{45 Sn. Sarkaç Koşusu } & Ön Test & 21 & 85,43 & 5,73 & 400 & & & & \\
\hline & Son Test & 21 & 81,43 & 7,90 & 4,00 & 10,28 & $1, / 8$ & 20 & 0,09 \\
\hline $12 \mathrm{Dr} \mathrm{D}_{\mathrm{K}}$ & Ön Test & 21 & 94,19 & 8,78 & 1100 & 1011 & 5.40 & 20 & 0 \\
\hline 12 DK. Koşu & Son Test & 21 & 82,29 & 8,79 & 11,90 & 10,11 & 5,40 & 20 & $0,00^{\pi}$ \\
\hline Norm Deăerler Tonlam & Ön Test & 21 & 531,90 & 31,49 & 1905 & 5205 & 168 & 20 & 011 \\
\hline & Son Test & 21 & 512,86 & 36,17 & 19,05 & 52,05 & 1,08 & & \\
\hline 7 & Ön Test & 21 & 88,33 & 5,31 & 319 & 862 & 170 & 20 & 011 \\
\hline & Son Test & 21 & 85,14 & 5,99 & 3,19 & 8,02 & $1, / 0$ & 20 & 0,11 \\
\hline Genel Der̆erlendirme & Ön Test & 21 & 4,38 & 0,67 & 010 & 0.04 & 0.46 & 20 & 0.65 \\
\hline Genel Degerlendırme & Son Test & 21 & 4,48 & 0,60 & $-0,10$ & 0,94 & $-0,40$ & 20 & 0,05 \\
\hline
\end{tabular}

$*_{\mathrm{p}}<0,05$ 
Urcan, T., \& İri, R. (2020). 14-16 yaş çocuklara uygulanan 8 haftalık antrenmanın motor performans üzerine etkisinin incelenmesi. Journal of Human Sciences, 17(4), 1094-1105. doi:10.14687/jhs.v17i4.6074

Tablo 3 incelendiğinde sarkaç koşusu ve üç adım atlama testlerinin ön test ve son test karşılaştırmasında anlamlı fark tespit edilmiştir $(p<0,05)$. Belirlenen farklığın sarkaç koşusu son test ölçüm değeri lehine, üç adım atlama testinde ise, ön test ölçüm değeri lehine olduğu tespit edilmiştir. Tablo 4 incelendiğinde sarkaç koşusu ve $12 \mathrm{dk}$. koşu testlerinde ön test lehine anlamlı bir fark tespit edilmiştir $(\mathrm{p} \leq 0,05)$.

Tablo 5. Sedanter katılımcılarının ön test ve son test ölçüm alt test değerlerinin karşılaştırıldığı t-testi

\begin{tabular}{|c|c|c|c|c|c|c|c|c|c|}
\hline \multirow{2}{*}{ Değişken } & \multirow{2}{*}{ Eşli Grup } & \multirow{2}{*}{$\mathrm{N}$} & \multirow{2}{*}{$\bar{x}$} & \multirow{2}{*}{ S } & \multicolumn{2}{|c|}{ İkili Arasındaki Farklar } & \multirow{2}{*}{$\mathrm{t}$} & \multirow{2}{*}{ sd } & \multirow[b]{2}{*}{$\mathrm{p}$} \\
\hline & & & & & $\bar{x}$ & $\mathrm{~S}$ & & & \\
\hline \multirow{2}{*}{ Sarkaç Koşusu } & Ön Test & 27 & 108,44 & 6,76 & \multirow{2}{*}{12,15} & \multirow{2}{*}{12,49} & \multirow{2}{*}{5,05} & \multirow{2}{*}{26} & \multirow{2}{*}{$0,00^{*}$} \\
\hline & Son Test & 27 & 96,30 & 10,61 & & & & & \\
\hline \multirow{2}{*}{$\begin{array}{c}\text { Sağllk Topu } \\
\text { Atma }\end{array}$} & Ön Test & 27 & 85,93 & 7,22 & \multirow{2}{*}{$-0,37$} & \multirow{2}{*}{8,04} & \multirow{2}{*}{$-0,24$} & \multirow{2}{*}{26} & \multirow{2}{*}{0,81} \\
\hline & Son Test & 27 & 86,30 & 5,97 & & & & & \\
\hline \multirow{2}{*}{$\begin{array}{l}\text { Üç Adım } \\
\text { Atlama }\end{array}$} & Ön Test & 27 & 77,70 & 8,35 & \multirow{2}{*}{0,89} & \multirow{2}{*}{9,60} & \multirow{2}{*}{0,48} & \multirow{2}{*}{26} & \multirow{2}{*}{0,63} \\
\hline & Son Test & 27 & 76,81 & 5,06 & & & & & \\
\hline \multirow{2}{*}{ Şınav (60 sn.) } & Ön Test & 27 & 83,70 & 8,20 & \multirow{2}{*}{$-3,19$} & \multirow{2}{*}{11,39} & \multirow{2}{*}{$-1,45$} & \multirow{2}{*}{26} & \multirow{2}{*}{0,16} \\
\hline & Son Test & 27 & 86,89 & 5,30 & & & & & \\
\hline \multirow{2}{*}{$\begin{array}{c}45 \text { Sn. Sarkaç } \\
\text { Koşusu }\end{array}$} & Ön Test & 27 & 91,04 & 12,56 & & $177^{\prime}$ & & & \\
\hline & Son Test & 27 & 89,11 & 11,57 & 1,93 & $1 /, 28$ & 0,58 & 20 & $0,5 /$ \\
\hline $12 \mathrm{Dk}$ Kosu & Ön Test & 27 & 96,44 & 11,04 & & & & & \\
\hline 12 & Son Test & 27 & 100,74 & 7,11 & & & 1,59 & 26 & 0,12 \\
\hline Norm Değerler & Ön Test & 27 & 544,81 & 37,69 & 867 & 3782 & 119 & 26 & 0.24 \\
\hline Toplam1 & Son Test & 27 & 536,15 & 23,51 & $8,0 /$ & $3 /, 82$ & 1,19 & 20 & 0,24 \\
\hline Z Değeri & Ön Test & 27 & 90,26 & 6,25 & 1,19 & 6,3 & 0,98 & 26 & 0,34 \\
\hline L Deger1 & Son Test & 27 & 89,07 & 3,96 & 1,19 & 0,31 & 0,98 & 20 & \\
\hline Genel & Ön Test & 27 & 4,15 & 0,82 & & & & 26 & 011 \\
\hline Değerlendirme & Son Test & 27 & 4,41 & 0,57 & $-0,20$ & 0,81 & $-1,00$ & 20 & 0,11 \\
\hline
\end{tabular}

Tablo 5 incelendiğinde sarkaç koşusu testi ön test ölçüm değeri lehine anlamlı bir farklılık tespit edilmiştir $(p<0,05)$. Tablo 6 incelendiğinde, gruplar arası karşılaştırma yapıldığında $(p<0,05)$ düzeyinde farkllıklar tespit edilmiştir. Alt değişkenlere göre genel olarak, voleybolcuların ortalamasının, basketbolcular tenisçiler ve sedanterlerden daha yüksek değerlere sahip olduğu, basketbolcuların ortalamalarının tenisçilerden ve sedanterlerden yüksek olduğu, tenisçilerin ortalamalarının sedanterlerin ortalamasından, sadece sarkaç koşusu alt testinde düşük diğer alt testte ise yüksek olduğu belirlenmiştir. 
Urcan, T., \& İri, R. (2020). 14-16 yaş çocuklara uygulanan 8 haftalık antrenmanın motor performans üzerine etkisinin incelenmesi. Journal of Human Sciences, 17(4), 1094-1105. doi:10.14687/ihs.v17i4.6074

Tablo 6. KTTT son test ölçüm alt test değerlerinin karşılaşturldığ1 ANOVA testi

\begin{tabular}{|c|c|c|c|c|c|c|c|c|c|c|c|}
\hline \multirow[b]{2}{*}{ Değişken } & \multirow[b]{2}{*}{ Grup } & \multirow[b]{2}{*}{$\mathrm{N}$} & \multirow[b]{2}{*}{$\overline{\mathrm{x}}$} & \multirow[b]{2}{*}{ S } & \multicolumn{4}{|c|}{ ANOVA } & \multirow[b]{2}{*}{$\mathrm{F}$} & \multirow[b]{2}{*}{$\mathrm{P}$} & \multirow{2}{*}{$\begin{array}{c}\text { Post- } \\
\text { hoc } \\
\text { Tukey }\end{array}$} \\
\hline & & & & & & $\mathrm{KT}$ & df & $\mathrm{KO}$ & & & \\
\hline \multirow{4}{*}{ Sarkaç Koşusu } & Voleybol & 25 & 108,16 & 4,96 & Gruplar Arası & 7998,44 & 3 & 2666,15 & \multirow{4}{*}{37,43} & \multirow{4}{*}{$0,00^{*}$} & V-S \\
\hline & Basketbol & 23 & 103,04 & 8,96 & Gruplar İçi & 6552,90 & 92 & 71,23 & & & V-T \\
\hline & Sedanter & 27 & 96,30 & 10,61 & Toplam & 14551,33 & 95 & & & & B-S \\
\hline & Tenis & 21 & 82,95 & 7,97 & & & & & & & $\begin{array}{l}\text { B-T } \\
\text { S-T }\end{array}$ \\
\hline \multirow{4}{*}{$\begin{array}{l}\text { Sağlık Topu } \\
\text { Atma }\end{array}$} & Voleybol & 25 & 95,36 & 7,80 & Gruplar Aras1 & 1386,56 & 3 & 462,19 & \multirow{4}{*}{9,48} & \multirow{4}{*}{$0,00 *$} & \\
\hline & Basketbol & 23 & 93,30 & 7,15 & Gruplar İçi & 4484,07 & 92 & 48,74 & & & $\mathrm{~V}-\mathrm{S}$ \\
\hline & Sedanter & 27 & 86,30 & 5,97 & Toplam & 5870,63 & 95 & & & & $\mathrm{~V}-\mathrm{T}$ \\
\hline & Tenis & 21 & 87,90 & 6,97 & & & & & & & B-S \\
\hline \multirow{4}{*}{$\begin{array}{l}\text { Üç Adım } \\
\text { Atlama }\end{array}$} & Voleybol & 25 & 92,96 & 6,66 & Gruplar Aras1 & 3819,13 & 3 & 1273,04 & \multirow{4}{*}{$-19,88$} & \multirow{4}{*}{$0,00 *$} & $\mathrm{~V}-\mathrm{S}$ \\
\hline & Basketbol & 23 & 89,57 & 11,33 & Gruplar İçi & 5891,83 & 92 & 64,04 & & & $\mathrm{~V}-\mathrm{T}$ \\
\hline & Sedanter & 27 & 76,81 & 5,06 & Toplam & 9710,96 & 95 & & & & B-S \\
\hline & Tenis & 21 & 84,57 & 8,18 & & & & & & & T-S \\
\hline \multirow{4}{*}{ Şınav (60 sn.) } & Voleybol & 25 & 107,12 & 7,55 & Gruplar Arası & 5762,67 & 3 & 1920,89 & \multirow{4}{*}{$-35,81$} & \multirow{4}{*}{$0,00 *$} & V-B \\
\hline & Basketbol & 23 & 91,48 & 7,01 & Gruplar İçi & 4935,33 & 92 & 53,65 & & & $\mathrm{~V}-\mathrm{S}$ \\
\hline & Sedanter & 27 & 86,89 & 5,30 & Toplam & 10698,00 & 95 & & & & $\mathrm{~V}-\mathrm{T}$ \\
\hline & Tenis & 21 & 93,71 & 9,37 & & & & & & & $\mathrm{~T}-\mathrm{S}$ \\
\hline \multirow{4}{*}{$\begin{array}{l}45 \text { Sn. Sarkaç } \\
\text { Koşusu }\end{array}$} & Voleybol & 25 & 104,72 & 12,18 & Gruplar Aras1 & 6906,89 & 3 & 2302,30 & \multirow{4}{*}{$-18,22$} & \multirow{4}{*}{$0,00^{*}$} & \\
\hline & Basketbol & 23 & 96,35 & 12,31 & Gruplar İçi & 11624,07 & 92 & 126,35 & & & $\mathrm{~V}-\mathrm{S}$ \\
\hline & Sedanter & 27 & 89,11 & 11,57 & Toplam & 18530,96 & 95 & & & & V-T \\
\hline & Tenis & 21 & 81,43 & 7,90 & & & & & & & B-T \\
\hline & Voleybol & 25 & 115,92 & 11,95 & Gruplar Aras1 & 15402,78 & 3 & 5134,26 & & & V-B \\
\hline & Basketbol & 23 & 88,70 & 10,49 & Gruplar İçi & 8708,18 & 92 & 94,65 & & & V-S \\
\hline 12 Dk. Koşu & Sedanter & 27 & 100,74 & 7,11 & Toplam & 24110,96 & 95 & & 54,24 & $0,00 *$ & V-T \\
\hline & Tenis & 21 & 82,29 & 8,79 & & & & & & & $\begin{array}{l}\text { S-B } \\
\text { S-T }\end{array}$ \\
\hline & Voleybol & 25 & 622,00 & 41,10 & Gruplar Aras1 & 159053,27 & 3 & 53017,76 & & & V-B \\
\hline & Basketbol & 23 & 566,48 & 35,75 & Gruplar İçi & 109211,72 & 92 & 1187,08 & & & V-S \\
\hline $\begin{array}{l}\text { Toplami } \\
\text { Tom }\end{array}$ & Sedanter & 27 & 536,15 & 23,51 & Toplam & 268264,99 & 95 & & 44,66 & $0,00 *$ & V-T \\
\hline & Tenis & 21 & 512,86 & 36,17 & & & & & & & $\begin{array}{l}\text { B-S } \\
\text { B-T }\end{array}$ \\
\hline & Voleybol & 25 & 103,32 & 6,86 & Gruplar Aras1 & 4400,81 & 3 & 1466,94 & & & V-B \\
\hline & Basketbol & 23 & 94,09 & 6,09 & Gruplar İçi & 3071,69 & 92 & 33,39 & & & V-S \\
\hline Z Değeri & Sedanter & 27 & 89,07 & 3,96 & Toplam & 7472,50 & 95 & & 43,94 & $0,00^{*}$ & V-T \\
\hline & Tenis & 21 & 85,14 & 5,99 & & & & & & & $\begin{array}{l}\text { B-S } \\
\text { B-T }\end{array}$ \\
\hline Genel & Voleybol & 25 & 2,72 & 0,79 & Gruplar Aras1 & 49,56 & 3 & 16,52 & & & V-B \\
\hline Değerlendirme & Basketbol & 23 & 3,61 & 0,78 & Gruplar İçi & 44,28 & 92 & 0,48 & & & V-S \\
\hline & Sedanter & 27 & 4,41 & 0,57 & Toplam & 93,83 & 95 & & 34,33 & $0,00 *$ & B-S \\
\hline & Tenis & 21 & 4,48 & 0,60 & & & & & & & $\begin{array}{l}v-1 \\
\text { B-T }\end{array}$ \\
\hline
\end{tabular}

${ }^{*} \mathrm{p}<0,05$; V: Volleybol; B: Basketbol; T: Tenis; S: Sedanter 
Urcan, T., \& İri, R. (2020). 14-16 yaş çocuklara uygulanan 8 haftalık antrenmanın motor performans üzerine etkisinin incelenmesi. Journal of Human Sciences, 17(4), 1094-1105. doi:10.14687/jhs.v17i4.6074

Tablo 7. Genel Değerlendirme puanları üzerinden sınıflandırmalarının yapıldığı yüzde ve frekans analizi

\begin{tabular}{|c|c|c|c|c|c|}
\hline \multirow{2}{*}{ Katulımcilar } & \multirow{2}{*}{ Kategorik Gruplar } & \multicolumn{2}{|c|}{ Ön Test } & \multicolumn{2}{|c|}{ Son Test } \\
\hline & & $\mathrm{N}$ & $\%$ & $\mathrm{~N}$ & $\%$ \\
\hline \multirow{6}{*}{ Voleybol } & Çok İyi & 0 & 0 & 1 & 4 \\
\hline & İyi & 6 & 24 & 8 & 32 \\
\hline & Normal & 11 & 44 & 14 & 56 \\
\hline & Yeterli & 5 & 20 & 1 & 4 \\
\hline & Yetersiz & 3 & 12 & 1 & 4 \\
\hline & Total & 25 & 100 & 25 & 100 \\
\hline \multirow{6}{*}{ Basketbol } & Çok İyi & 0 & 0 & 0 & 0 \\
\hline & İyi & 2 & 8,7 & 2 & 8,7 \\
\hline & Normal & 10 & 43,5 & 7 & 30,4 \\
\hline & Yeterli & 8 & 34,8 & 12 & 52,2 \\
\hline & Yetersiz & 3 & 13 & 2 & 8,7 \\
\hline & Total & 23 & 100 & 23 & 100 \\
\hline \multirow{6}{*}{ Tenis } & Çok İyi & 0 & 0 & 0 & 0 \\
\hline & İyi & 0 & 0 & 0 & 0 \\
\hline & Normal & 2 & 9,5 & 1 & 4,8 \\
\hline & Yeterli & 9 & 42,9 & 9 & 42,9 \\
\hline & Yetersiz & 10 & 47,6 & 11 & 52,4 \\
\hline & Total & 21 & 100 & 21 & 100 \\
\hline \multirow{6}{*}{ Sedanter } & Çok İyi & 0 & 0 & 0 & 0 \\
\hline & İyi & 1 & 3,7 & 0 & 0 \\
\hline & Normal & 4 & 14,8 & 1 & 3,7 \\
\hline & Yeterli & 12 & 44,4 & 14 & 51,9 \\
\hline & Yetersiz & 10 & 37 & 12 & 44,4 \\
\hline & Total & 27 & 100 & 27 & 100 \\
\hline
\end{tabular}

Tablo 7 incelendiğinde, ön test ölçümlerinde voleybolcuların \%68'nin normal ve üstündeki kategorilerde yer aldığ 1 son testte ise \%92'sinin normal ve üstündeki kategorilerde yer aldığ1, basketbolcuların ön testte $\% 52$,2'sinin normal ve üstündeki kategorilerde yer aldığ1, son testte ise \% 82,6'sının normal ve yeterli kategorilerinde yer aldığ1 tenisçilerin ön testte \%52,4'sinin normal ve yeterli kategorilerinde yer aldığ1, son testte ise \%47,7'sinin normal ve yeterli kategorilerinde yer aldığı, sedanter katılımcıların ön testte \%96,2’ ünün normal ve altındaki kategorilerde yer aldığ1 son testte ise \% 96,3’ünün yeterli ve yetersiz kategorilerinde yer aldığ1 tespit edilmiştir.

\section{Tartışma ve Sonuç}

Bir motor hareketin, yapilabilme düzeyine motor performans denir. Motor performans, doğrudan gözlemlenebilir (Özer ve Aktop, 2014). Yapılan çalışmanın amacı farklı branşlarda antrenman yapan, 14-16 yaş kadınlara uygulanan 8 haftalık tenis, voleybol ve basketbol branş antrenmanının motor performans gelişimleri üzerine etkisinin incelenmiştir. Bir motor hareketin, yapılabilme düzeyine motor performans denir. Motor performans, doğrudan gözlemlenebilir (Özer ve Aktop, 2014). Yapılan çalışmanın amacı farklı branşlarda antrenman yapan, 14-16 yaş kadınlara uygulanan 8 haftalık tenis, voleybol ve basketbol branş antrenmanının motor performans gelişimleri üzerine etkisinin incelenmiştir. Yapılan çalışmanın sonucuna bakıldı̆̆ında, 8 hafta boyunca uygulanan branş antrenmanlarının, motor performans düzeyleri üzerine olumlu yönde gelişim sağladığı tespit edilmiştir.

Sedanter grupta sarkaç koşusunda, meydana gelen gelişimin ise 14 -16 yaş grubunda bulunan çocukların sporla ilişkili hareketler döneminde yer almaları ve çocukların gelişim döneminde olmaları ile ilgili olduğu düşünülmektedir. Elde edilen bulgular sonucunda, antrenman gruplarının 
Urcan, T., \& İri, R. (2020). 14-16 yaş çocuklara uygulanan 8 haftalık antrenmanın motor performans üzerine etkisinin incelenmesi. Journal of Human Sciences, 17(4), 1094-1105. doi:10.14687/ihs.v17i4.6074

sedanter gruba göre, daha iyi motor performans düzeyine sahip olduğu ve yapılan antrenmanların çocukların motor performans gelişimlerine katk1 sağladığı sonucuna ulaşılmıştır. Uygulanan 8 haftalık antrenman, her antrenman grubuna aynı düzeyde etki sağlamamıştır. Voleybol ve basketbol antrenman gruplarının, diğer gruplara oranla daha iyi gelişim göstemesiyle birlikte, tenis antrenman grubunda da bir gelişim sağlanmıştır. Voleybolcuların ve basketbolcuların diğer antrenman gruplarından, daha yüksek puanlar elde etmeleri, uygulanan branş içi antrenman metotlarının çocukların motor performans düzeylerini geliştirecek çeşitlilikte olmasıyla bağdaşturılabilir. Tenisçiler, bu yönü ile voleybol ve basketbol branşlanından daha zayıf kalmışlardır. Çalışmamıza benzer bir araştırmada, Douvis ve ark. (2008) 13-15 yaş grubu kadın ve erkeklerde tenis oynayan ve tenis oynamayan bireylere, Tenis Konditions Testi'ni uygulamışlardır. Sonuç olarak bu yaş grubu, erkek grupta anlamlı bir fark bulunmazken, kadınların grup içi karşılaştırması incelendiğinde anlamlı bir fark tespit edilmiş ve ortaya çıkan bu farklılı̆ıın, tenis oynayan kadınların lehine olduğunu belirtmişlerdir. Literatür incelendiğinde, çalışmamızın amacına benzer fakat farklı branşlarda ve farklı motor performans testleri kullanılarak yapılan çalışmalar mevcuttur. Öztekin (2019) 10-12 yaş arası çalışmaya kattlan en az 2 yıl spor geçmişi olan futbol oynayan çocuklara 8 haftalık futbol beceri antrenmanı uygulamış olup, 8 haftanın sonucunda Körper Koordinations Test Für Kinder (KTK) ile motor performanslarını ölçmüştür. KTK Genel değerlendirme oranlarına bakııldığında, 30 kişilik denek grubunun \% 63, 3' ünün normal kategorisinde yer aldığını belirtmiştir. KTK testine göre, çocukların motor beceri gelişimlerinin olumlu yönde artış meydana geldiğini belirtmiştir. Gül ve ark. (2020) 13-14 yaş grubu kadın voleybolcularda 8 haftalık plyometrik antrenman metodunun motorik özelliklere etkisini incelemişlerdir. Çalışma sonucuna göre, kontrol ve deney grubunun 20 metre sürat koşusu testi sonuçları karşılaştırıldığında anlamlı bir fark olduğu farkın deney grubu lehine olduğunu belirtmişlerdir. 13-14 yaş grubundaki voleybolcularda antrenmanın sürat performans1 üzerine olumlu etkisi olduğunu belirtmişlerdir. Yapılmıs başka bir çalısmada, Banks (2020) yaptığı çalışmada, adolesan kadın basketbolculara 6 haftalık antrenmanın bazı fiziksel özelliklerinin üzerine etkilerini incelemiştir. Çalışma sonucunda, adolesan basketbolcuların sıçrama özelliğini geliştirdiğini bildirmiştir. Rajech ve ark. (2020) yapmış oldukları çalışmada, 14-16 yaş grubu hokey oyuncuları üzerinde, 6 haftalık antrenmanın motor performans üzerine etkisini araştırmışlardır. Katılımcıların motorik özelliklerini ölçen testler uygulamışlardır. Çalışmanın sonucunda ise, yapılan 6 haftalık antrenmanın bu yaş grubunun motorik özelliklerini geliştirdiklerini tespit etmişlerdir. Yapılan başka bir çalışmada, genç tenisçilerin kaba motor koordinasyon performans seviyelerini belirlemek, yaş ve cinsiyet etkilerini analiz etmeyi amaçlayan bir çalışmada katılan, toplamda 101 çocuğun yaşları 6-14 arasındadır. Körperkoordination-Test-für-Kinder (KTK) motor beceri test protokolünün uygulandığ1 çalışmada sonuç olarak, katulımcıların \%40,6's1 normal seviyenin üzerinde performans göstermiştir. KTK' nın tüm alt testlerinde ve ayrıca toplam motor puan bölümünde cinsiyete dair bir fark bulunmamıştır.

Diğerlerine göre yaşı büyük oyuncular ham puanlar için kendilerinden yaş olarak küçük oyunculara göre daha iyi performans gösterseler de, farklı yaş grupları arasında toplam motor puanları üzerinde anlamlı bir etki gözlenmemiştir.(Sögüt, 2016). Fernandez ve ark. (2014) yapmış oldukları çalışmada, Alman tenis federasyonu bünyesindeki farklı yaş ve kategorilerinde bulunan, 10-18 yaş arası 1052 tenisçiye uygulamışlardır. İçeriğinde KTT 'yide barındıran, DMT durum testini uygulamışlardır. hem cinsiyet farklılı̆ı dikkatte alınarak hem de yaş kategorilerine göre yapılan motor performans testleri sonucunda, sporcularnn yaş ve cinsiyet kategorilerine göre gelişim gösterdiği ve tenisçilerin çoğunluğunun normal ve üst seviyedeki kategorilerde yer aldığ1, öneri olarak ise, motor performans gelişimi için bireysel farklılıkların göz önüne alınarak antrenman içeriği olması gerektiğini belirtmişlerdir. Bu çalışmaya benzer olan kısımları KTT’nin 14-16 yaş grubunda yapılan motor alt test sonuçları bakımından benzerlik göstermektedir. Sögüt (2019) 6-14 yaş arası 101 tenis oynayan çocuk üzerinde yaptığ1 çalışmada çocukların \%41'inin yüksek ve iyi kategorilerinde olduğunu belirlemiştir.

Literatürdeki birçok çalışma bulgularımızı destekler niteliktedir. Sonuç olarak bu yaş grubundaki çocukların, motor performans gelişimlerini artırabilmek için, hem ergenlik öncesi hem 
Urcan, T., \& İri, R. (2020). 14-16 yaș çocuklara uygulanan 8 haftalık antrenmanın motor performans üzerine etkisinin incelenmesi. Journal of Human Sciences, 17(4), 1094-1105. doi:10.14687/jhs.v17i4.6074

ergenlik döneminde yetenekleri doğrultusunda sportif faaliyetlere yönlendirilmesinin ve motor performans gelişimini destekleyecek türde antrenmanlar uygulanmasının önemli olduğu düşünülmektedir. Aynı zamanda yerli literatürde kullanımı sınırlı olan KT'T test protokolünün uygulamış olduğumuz birçok branşta uygulanabilirliğini gösteren bulgular elde edilmiştir. Bu sebeple gelecekte yapılacak çalışmalarda daha geniş örneklem grubu ve farklı branşlarda uygulanması önem arz etmektedir.

\section{Kaynakça}

Banks, S. (2020). The Effects of a 6-Week Plyometric Exercise Program on Vertical Jump Height and Perceived Physical Ability in Adolescent Female Basketball Players (Doctoral dissertation, California State University, Fresno).

Çoknaz, H. (2017). Doğum öncesinden ölüme kadar Psikomor gelişim. Gazi Kitapevi, Ankara.

Douvis, S., Mavidis, A., Mallios, VJ., Dallas, G. (2008). Evaluation of Greek tennis players (13-15 years old) with the German set of field tests-KTT. International Journal of Fitness, 4 (1).

Eren, E. (2019). 12-14 yaş grubu tenisçilerde 8 haftalık core antrenmanın yer vuruş hızlarına ve bazı motorik özelliklere etkisinin incelenmesi (Master's thesis, Bartın Üniversitesi, Sosyal Bilimler Enstitüsü).

Fernandez-Fernandez, J., Ulbricht, A., \& Ferrauti, A. (2014). Fitness testing of tennis players: How valuable is it?. British journal of sports medicine, 48(Suppl 1), i22-i31.

Fransen, J., Pion, J., Vandendriessche, J., Vandorpe, B., Vaeyens, R., Lenoir, R., Philippaerts, R.M. (2012). Differences in physical fitness and gross motor coordination in boys aged 6-12 years specializing in one versus sampling more than one sport. J Sports Sci, 30(4), 379-386.

Gallahue, DL., Ozmun, J., Goodway, JD. (2014). Motor gelişimi anlamak bebekler, çocuklar, ergenler, yetişkinler. Sevimay Özer, D ve Aktop, A. (Çeviri Ed.leri). Ankara: Nobel Akademik Yayıncilik.

Gül 1a, M., Eskiyecek 2b, Cg, Şeşen 1c, H. Ve Gül 1d, Gk (2020). Voleybolcu Kadınlarda Plyometrik Egzersizlerin Çeşitli Motorik Özelliklerine Etkisinin Belirlenmesi. Türk Spor ve Egzersiz Dergisi, 22(1), 38-43

Leppanen, M.H., Nystrom, C.D., Henriksson, P., Pomeroy, J., Ruiz, J.R., Ortega, F.B., CadenasSanchez, C., and Lof, M. (2016). Physical activity intensity, sedentary behavior, body composition and physical fitness in 4-year-old children: Results from the ministop trial. Int. J. Obes., 40, 1126-1133.

Öztekin, B. (2019). 10-12 yaş grubu çocuklara uygulanan futbol beceri antrenmanının motor beceri geilşimlerinin üzerine etkisinin incelenmesi, Yüksek Lisans Tezi, Niğde Ömer Halisdemir Üniversitesi, Sosyal Bilimler Enstitüsü, Niğde

Özer, D. S., Aktop, A. (Ed.) (2014). Motor Gelişimi Anlamak (7. baskı). Ankara: Nobel Yayincilik.

Rajesh, M., Babu, G., \& Kumar, B. S. Effect of 6 Weeks Training on the Physical Fitness Performance of Girls Hockey Players at Hyderabad District.

Robinson, L. E., Stodden, D. F., Barnett, L. M.,Lopes, V. P., Logan, S. W., Rodrigues, L. P., D'Hondt, E., (2015). Motor competence and its effect on positive developmental trajectories of health. Sports Medicine, 45(9);1273-1284. doi:10.1007/s40279-015-0351-6 .

Sackett, S. C., Edwards, E. S. (2019). Relationships among motor skill, perceived self-competence, fitness, and physical activity in young adults. Human Movement science, 66, 209-219.

Sayın, M., (2011). Hareket ve Beceri Öğrenimi. Spor Yayınevi ve Kitapevi, Ankara, 61.

Sögüt, M. (2017). A comparison of serve speed and motor coordination between elite and club level tennis players. Journal of Human Kinetics, 55(1):171-176.

Sögüt, M. (2016). Gross motor coordination in junior tennis players, Journal of Sports Sciences. 34(22): 2149-2152. 
Urcan, T., \& İri, R. (2020). 14-16 yaş çocuklara uygulanan 8 haftalık antrenmanın motor performans üzerine etkisinin incelenmesi. Journal of Human Sciences, 17(4), 1094-1105. doi:10.14687/ihs.v17i4.6074

Timmons, B.W., Naylor, P.J. Pfeiffer, K.A. (2007). Physical activity for preschool children: How much and how? C J Public Health, 98, 122-134.

Utley A. (2019) Motor Control, Learning and Development. Second edition published, New York, NY 10017

Vandorpe, B., Vandendriessche, JB, Vaeyens, R., Pion, J., Lefevre, J., Philippaerts, RM, and Lenoir, M. (2012). The value of a non-sport-specific motor test battery in predicting performance in young female gymnasts. Journal of Sports Sciences, 30(5), 497-505.

\section{Extended English Summary}

Advances in sports and athlete performance work in recent years attracts great attention. New research, testing new training methods contributing to the improvement of the performances of its athletes and accumulation (Utley, 2019). Sports scientists, lately the motor performance of children and adolescents they increased their efforts to determine their situation Leppanen et al (2016). The reason for this is the physical health of engine performance and it is an element that shows their sportive success Van Dorpe et al (2012). The orientation of children to different sports branches, differences in motor performance levels in children according to their needs may cause. When the literature in this field is examined, There are few studies examining the motor performance of adolescent children. In a study on adolescents, 14-16 years old children, considering the gender factor conducted a comprehensive research and in this study, motor performance according to gender They investigated how it changed. Sackett et al (2019). In early adolescence, height grows rapidly and as a result some reveals negativities. The muscular system is sufficient for the skeletal system that stretches and develops and the leverage system in the body cannot keep the force-load ratio in balance and hormones are more active, so children spend their most inefficient period in terms of strength. they live. However, towards the end of adolescence, strength development reaches the highest value reaches. When the height growth is completed in men, the development of strength increases significantly. The reason for this is the increase in muscle mass due to high testosterone levels can be explained with for women, the situation is the opposite. Of the estrogen hormone 18 with the secretion, the increase in body fat ratio starts in women, so the muscle in women there are more fat cells instead. In addition, miscarriage during puberty in women the reason for obtaining the data is not only the size change but also it is a lack of motivation. (Çoknaz, 2017). In the study, women who train in different branches determination of engine performance levels and in different branches The effects of training on motor performance were examined. Study participant Participation of 14-16 year old children in 8-week training constitutes importance. The results of the study, to be done in this area It is thought to contribute to the studies. Also applied in the study Tennis Condition test KTT developed by the German Tennis Federation express the originality of the work that the children have not been previously applied in Turkey. As a result, after 8-week training sessions in different branches, it was determined that the motor performance levels of the groups performing 8 weeks training in 14-16 years old children were better than the non-training sedentary group according to the KTT Tennis Condition Test. The 8week training has influenced children's motor performance development. In order to increase the motor performance development of children in this age group, it is thought that it is important to direct the children to sportive activities in line with their abilities, and to provide the training that supports the motor performance development.

As a result, it is recommended that;

- Attention should be paid to the development of motor skills and coordination characteristics of adolescents and pre-adolescents. It is important to direct the child to choose a branch in line with his abilities. 
Urcan, T., \& İri, R. (2020). 14-16 yaş çocuklara uygulanan 8 haftalık antrenmanın motor performans üzerine etkisinin incelenmesi. Journal of Human Sciences, 17(4), 1094-1105. doi:10.14687/ihs.v17i4.6074

- Children who have entered the period related to sports may be in the most productive period in terms of their sportive abilities, and may be under the influence of adolescence and may be inadequate in many motor skills. The training activities to be applied should be in a way to meet the needs of this age group.

- Care should be taken to ensure that the exercises to be applied in children aged 14-16 are in a way that will develop their motor performance and motor skills.

- Since the age group of 14-16 is a special age range in the development of sportive performance, the chosen training methods should be selected and applied considering both the gender factor and the developmental characteristics of this age group.

- In training methods applied to women aged 14-16; Basic studies that will improve motor performance such as speed, speed, coordination, endurance should be included.

- Every child of this age should be encouraged to do sports through clubs, youth sports training groups or school teams.

- In terms of the results obtained, it can be recommended to use the KTT "Tennis Condition Test" not only in tennis but also in other branches. 